JURNAL PENJAMINAN MUTU

LEMBAGA PENJAMINAN MUTU

UNIVERSITAS HINDU NEGERI

I GUSTI BAGUS SUGRIWA DENPASAR

\title{
EFEKTIVITAS PEMANFAATAN MEDIA E-LEARNING DENGAN MOODLE DALAM MENJAGA MUTU PEMBELAJARAN SAAT BELAJAR DARI RUMAH
}

\author{
Oleh \\ Ramen Antonov Purba \\ Politeknik Unggul LP3M-Medan \\ ramenantonovpurba@gmail.com
}

diterima 30 Mei 2021, direvisi 23 Juni 2021, diterbitkan 31 Agustus 2021

\begin{abstract}
Education is an effort to gain knowledge, expertise and competence. The journey of education cannot stop. The presence of Covid-19 has resulted in transformations in the education sector. Learning activities have to be done at home. The parameters of each component used in learning activities are expected to produce good results. Thus, the use of e-learning with Moodle. The target is for students to gain knowledge and good results. E-learning with Moodle is an option based on its internet-based work pattern. No place limit and no time limit. A vital evaluation step is carried out. Higher education institutions are required to be professionals. Higher education institutions also face evaluation from LLDIKTI. Internal evaluation is mandatory. All existing elements must be committed to carrying out these obligations. Accommodating agreed targets. Making students understand teaching material. Opening students' insights and thoughts. Students can complete it and get maximum results (sound). The research conducted will look at the effectiveness of using $e$ learning media with Moodle in maintaining the quality of learning when learning from home. The method used to conduct research is an experiment. The subjects of the Politeknik Unggul LP3M Medan students, the Informatics Management study program are 32 students. Found that the functional level and value accumulation using moodle-based e-learning media with the dynamics of learning from home can maintain and maintain quality. All learning activities go well as expected and targeted.
\end{abstract}

Keywords: E-learning, Moodle, Quality, Covid-19 Pandemic

\section{PENDAHULUAN}

Pendidikan dikatakan sebagai usaha guna memperoleh pengetahuan, keahlian, serta kompetensi. Oleh sebab itu, perjalanan pendidikan tidak bisa berhenti, meskipun terjadi situasi serta kondisi diluar dugaan 
(Verawardina \& Jama, 2018). Kehadiran Covid-19 yang tidak diduga mengakibatkan terjadinya tranformasi diseluruh elemen, termasuk pendidikan. Kebijakan wajib menjaga jarak serta menghindari kerumunan demi memutus rantai penyebaran mengakibatkan aktivitas pembelajaran terpaksa dilakukan di rumah (Purba, 2020).

Struktural manajemen Politeknik Unggul LP3M Medan, pada awal-awal diterbitkannya kebijakan belajar dari rumah, sedikit mengalami kendala. Tidak adanya persiapan menghadapi situasi diluar dugaan, menjadikan seluruh struktural berpikir keras terkait model serta sistem pembelajaran yang akan dilaksanakan (Purba \& Verawardina, 2021). Hingga akhirnya diputuskan melaksanakan pembelajaran secara online dengan konteks e-learning. Kemudian disepakati bahwa moodle yang akan dipergunakan. Moodle merupakan salah satu sistem pembelajaran yang dapat diakses secara mudah karena sifatnya yang terbuka. Serta tidak berbayar (gratis) (Muhammad et al., 2020). Pihak UPT Sistem Informasi membangun dan melakukan settingan aplikasi, untuk kemudian dipublikasikan kepada dosen sebagai pengajar, serta mahasiswa sebagai peserta pembelajaran.

Adapun parameter setiap komponen yang dimanfaatkan dalam aktivitas pembelajaran adalah bagaimana komponen yang dimanfaatkan tersebut mampu mewujudkan hasil yang baik sesuai dengan target pembelajaran. Demikian pula dengan dimanfaatkannya media e-learning dengan moodle. Targetnya tetap agar mahasiswa mendapatkan pengetahuan, serta hasil yang baik ketika dilakukan proses test atau ujian. $E$ learning dengan moodle menjadi pilihan didasarkan pada pola kerjanya yang berbasis jaringan internet (Rijal \& Sofiarini, 2019). Dapat dibuka serta dimanfaatkan tanpa batas tempat, serta tidak terbatas waktu. Selama si pengguna terhubung dalam jangkauan jaringan operator tertentu.

(Irawan \& Surjono, 2018) mengatakan jika e-learning merupakan media pembelajaran yang efektif, karena mampu mengakomodir proses belajar tanpa batas wilayah begitupula waktu. (Fatmawati, 2019) pada penelitiannya mengungkapkan bahwa moodle merupakan media LMS yang baik, karena terkoneksi dengan internet. Sehingga dapat dengan dinamis dipergunakan. (Rizal \& Walidain, 2019) menyimpulkan sesuai dengan penelitiannya, bahwa konteks pembelajaran dengan menggunakan jaringan, dalam hal ini moodle berbasis e-learning, sangat layak dan baik dipergunakan pada situasi tidak normal. Pemikiran demikian sesungguhnya yang menjadi dasar manajemen Politeknik Unggul LP3M memutuskan menggunakan media e-learning dengan moodle sebagai wadah pembelajaran di civitas akademika Politeknik Unggul LP3M di situasi pandemi Covid-19 yang menyebabkan pembelajaran wajib dilakukan dari rumah.

Dosen secara rutin melakukan aktivitas mengajar sesuai dengan jadwal yang telah ditetapkan menggunakan moodle. Setiap pembelajaran terdapat sesi membagikan materi, memberikan tugas, bahkan melakukan quiz, uts, maupun uas. Mahasiswa juga melakukan aktivitas yang sama sebagai respon dari yang dilakukan oleh dosen. Jika dosen memberikan materi ajar, maka mahasiswa mengunduh materi tersebut kemudian menyimpannya untuk dipelajari di komputer atau laptop yang mereka miliki. Ketika diberikan tugas, mahasiswa mengerjakan kemudian mengirimkan kembali melalui moodle sesuai dengan waktu yang ditentukan. Demikian pula untuk quiz, uts, serta uas.

Kendala di awal ketika pertama kali dilakukan aktivitas pembelajaran melalui moodle adalah pengisian paket agar jaringan internet dapat diakses. Tidak hanya pada dosen, mahasiswa juga mengalami permasalahan yang serupa. Namun permasalahan tersebut dapat diatasi dengan diberikannya subsidi dari pemerintah melalui kemendikbud. Oleh sebab itu, setelah menjalani aktivitas pembelajaran dari rumah selama beberapa saat, tentu harus dilakukan evaluasi terhadap perjalanan aktivitas pembelajaran yang telah dilakukan. Untuk melihat apakah seluruh aktivitas 
pembelajaran berjalan sesuai dengan yang ditetapkan. Berikutnya apakah media yang disediakan, dalam hal ini media e-learning dengan moodle memang mumpuni dipergunakan sebagai media pembelajaran (Sudarmanto et al., 2021).

Langkah evaluasi ini penting dilaksanakan, mengingat institusi pendidikan tinggi tetap dituntut profesional dalam operasional pembelajarannya meskipun di situasi tidak normal akibat Covid-19 (Khasanah et al., 2020). Karena akan tiba waktunya institusi pendidikan tinggi juga menghadapi pemeriksaan dalam bentuk evaluasi dari LLDIKTI untuk melihat apakah setiap aktivitas berjalan dengan baik, serta tidak ada tahapan dan aktivitas illegal yang dilakukan. Oleh sebab itu, langkah evaluasi internal sangat wajib guna dilakukan. Seluruh elemen yang ada di Politeknik Unggul LP3M Medan juga berkomitmen untuk melaksanakan kewajiban tersebut. Tidak bisa langkah individual dilakukan, karena langkah individual hanya akan menjadikan langkah yang dilakukan menjadi tidak maksimal.

Memang terjadi transformasi pembelajaran dari yang umumnya bertemu langsung (tatap muka) ke sistem e-learning dengan moodle. Tetapi secara umum, pemanfaatan media dengan wujud demikian bukanlah permasalahan, karena dosen serta mahasiswa sudah terbiasa dengan teknologi (Jamaludin et al., 2020). Pesatnya perkembangan teknologi secara pasti sudah diadopsi oleh dosen begitupula mahasiswa. Hal ini terlihat dari jumlah pengguna internet di Indonesia sangat tinggi (Mudawamah, 2020). Bahkan aktivitasnya lalu lintas pemanfaatan jaringannya juga sangat padat. Oleh sebab itu yang penting untuk ditelusuri adalah tingkat efektivitas pemanfaatan dalam hal ini media e-learning dengan moodle. Apakah mampu mengakomodir target yang telah disepakati. Apakah berhasil menjadikan mahasiswa memahami materi ajar yang ditransferkan oleh dosen. Apakah berhasil membuka wawasan serta pemikiran mahasiswa, sehingga ketika ujian dilaksanakan, mahasiswa mampu menyelesaikannya serta memperoleh hasil yang maksimal (baik).

Penelitian akan melihat efektivitas pemanfaatan media e-learning dengan moodle dalam menjaga mutu pembelajaran saat belajar dari rumah. Sehingga akan dapat dilihat apakah e-learning dengan moodle mampu atau tidak mampu dalam menghadirkan mutu pembelajaran di situasi tidak normal.

\section{METODE}

Metode yang dipergunakan untuk melakukan penelitian yakni eksperimen (Juita, 2019). Karena metode ini dapat melihat pengaruh pada kondisi tertentu. Penelitian berlangsung di Politeknik Unggul LP3M Medan. Subjek mahasiswa Politeknik Unggul LP3M Medan, program studi Manajemen Informatika sejumlah 32 mahasiswa. Diklasifikasikan 30 mahasiswa berjenis kelamin laki-laki, serta 2 mahasiswa berjenis kelamin perempuan.

Dalam perjalanannya, mahasiswa akan diminta untuk memberikan penilaian dengan menjawab pertanyaan secara terurut. Jumlah pertanyaan yang harus diberikan jawaban sejumlah 20 pertanyaan. Berhubung karena situasi masih masa pandemi Covid-19, pembagian lembar isian serta pelaksanaan pemberian jawaban oleh mahasiswa, diisikan melalui google form.

\section{PEMBAHASAN}

Adapun yang menjadi parameter sesuai dengan yang ditetapkan dalam menilai mutu pembelajaran yakni di kriteria aktif serta nilai yang merupakan perolehan hasil belajar. Untuk kriteria aktif diperhatikan dari beberapa aspek, seperti pada tabel 1 :

\section{Tabel 1}

Penjabaran Kriteria Aktif

\begin{tabular}{|c|c|l|}
\hline Urutan & Komponen & \multicolumn{1}{|c|}{ Aspek } \\
\hline 1 & Fokus & Mahasiswa \\
& & fokus dengan \\
& & penjelasan \\
& & serta materi \\
& & ajar r yang \\
\hline
\end{tabular}




\begin{tabular}{|c|l|l|}
\hline & & dipaparkan \\
& dosen \\
\hline 2 & Responsif & Mahasiswa \\
& merespon \\
dengan baik \\
apa yang \\
disampaikan \\
\end{tabular}

Agar proses pengukuran aktif dapat berjalan secara jelas dan lengkap, dibutuhkan acuan penilaian. Acuan penilaian merupakan dasar. Adapun acuan penilaian yang disepakati untuk kriteria aktif, seperti pada tabel 2 :

Tabel 2

Acuan Penilaian Keaktifan

\begin{tabular}{|c|l|}
\hline Angka & \multicolumn{1}{|c|}{ Indikasi } \\
\hline 5 & Aktif Sekali \\
\hline 4 & Aktif \\
\hline 3 & Cukup Aktif \\
\hline 2 & Kurang Aktif \\
\hline 1 & Sangat Tidak Aktif \\
\hline
\end{tabular}

Kemudian untuk kriteria nilai berdasarkan perolehan hasil belajar, ditarik kesimpulan berdasarkan nilai setiap mata kuliah yang menjadi mata kuliah yang wajib dipelajari pada semester tersebut. Untuk penjabarannya seperti pada tabel 3 :

Tabel 3

Penjabaran Nilai Hasil Belajar

\begin{tabular}{|c|c|c|}
\hline Urutan & $\begin{array}{c}\text { Rentang } \\
\text { Nilai }\end{array}$ & Persepsi \\
\hline 1 & $0-21$ & Buruk \\
\hline 2 & $22-41$ & Tidak Baik \\
\hline 3 & $42-61$ & Sedang \\
\hline 4 & $62-81$ & Lulus \\
\hline 5 & $82-100$ & Mengagumkan \\
\hline
\end{tabular}

Guna mendapatkan hasil kriteria aktif seperti yang dipaparkan pada tabel 1, melalui penilaian dosen. Jadi dosen yang memiliki otoritas mmemberikan penilaian, sesuai dengan apa kenyataan yang terjadi sewaktu aktivitas belajar berjalan. Didapatkan angka seperti pada tabel 4 berikut :

Tabel 4

Value Kriteria Aktif

\begin{tabular}{|c|c|}
\hline Eksplanasi & Angka \\
\hline Rerata & 3,12 \\
\hline Nilai Tengah & 3,05 \\
\hline Sering Muncul & 2,75 \\
\hline Persebaran Angka & 0,62 \\
\hline Angka Minimal & 2,25 \\
\hline Angka Maksimal & 4,50 \\
\hline Probabilitas & 0,38 \\
\hline Ketidaksimetrisan & 0,66 \\
\hline Error Rerata & 0,41 \\
\hline Derajat Runcing & 0,09 \\
\hline E Derajat Keruncingan & 0,81 \\
\hline
\end{tabular}

Dari tabel 4 didapati level aktif mahasiswa diklasifikasikan aktif. Rerata pada angka 3,12. Berikutnya dapat pula dilakukan pengklasifikasian tingkat keaktifan seperti di tabel 5 : 
Tabel 5

Klasifikasian Keaktifan Mahasiswa

\begin{tabular}{|c|c|c|c|}
\hline Intensitas & Rentan & $\%$ & Ket \\
\hline 0 & $0-1,1$ & $-\%$ & Buruk \\
\hline 0 & $1,2-2,1$ & $-\%$ & Kurang \\
\hline 17 & $2,2-3,1$ & $53,125 \%$ & Sedang \\
\hline 12 & $3,2-4,1$ & $37,5 \%$ & Bagus \\
\hline 3 & $4,2-5$ & $9,375 \%$ & Ideal \\
\hline 32 & Total & $100 \%$ & \\
\hline
\end{tabular}

Sesuai dengan tabel 5 kemudian dilakukan pengkonversian dalam bentuk lingkaran diagram dengan bentuk seperti lingkaran diagram 1 :

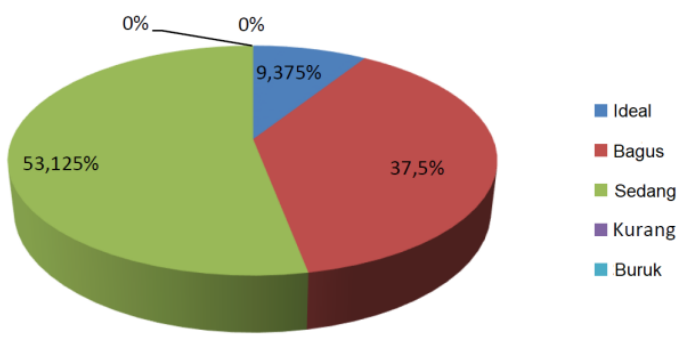

\section{Lingkaran Diagram 1. Konversi Level Aktif Mahasiswa}

Sesuai dengan tabel 5 yang kemudian di konversi ke lingkaran diagram 1, dapat dilihat tingkat aktif di level sedang ada di angka 53\% lebih. Untuk level bagus ada di angka 37\% lebih. Serta untuk level ideal ada di angka 9\% lebih. Sehingga dapat ditarik benang merah berbentuk kesimpulan, jika kriteria level aktif, dapat dikatakan aktif. Benang merah ini dapat dikonversi ke bentuk diagram batang 1 :

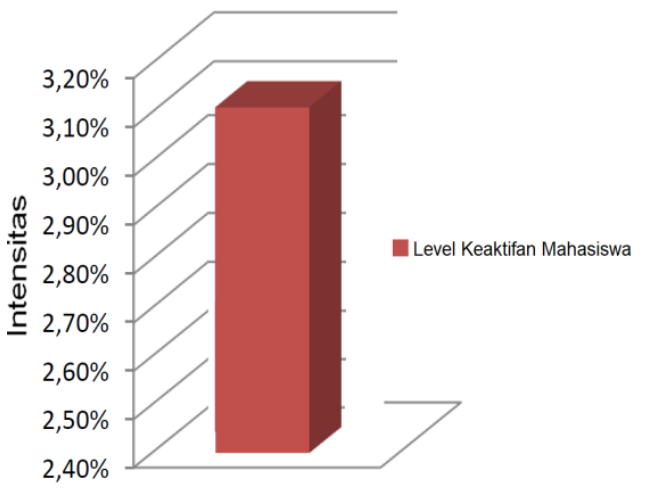

Diagram Batang 1. Persentase Level Aktif Mahasiswa

Untuk hasil belajar mahasiswa sesuai dengan mata kuliah yang dipelajari sesuai dengan semesternya, dapat dijabarkan di tabel 5 berikut:

Tabel 6

Value Hasil Belajar

\begin{tabular}{|c|c|}
\hline Eksplanasi & Angka \\
\hline Rerata & 76,9 \\
\hline Nilai Tengah & 76,25 \\
\hline Sering Muncul & 75,00 \\
\hline Persebaran Angka & 4,53 \\
\hline Angka Minimal & 65,00 \\
\hline Angka Maksimal & 85,00 \\
\hline Probabilitas & 20,54 \\
\hline Ketidaksimetrisan & $0,19(-)$ \\
\hline Error Rerata & 0,41 \\
\hline Derajat Runcing & 0,12 \\
\hline E Derajat Keruncingan & 0,81 \\
\hline
\end{tabular}

Berdasarkan tabel 6 didapati rerata hasil belajar mahasiswa di angka 76,9. Angka tersebut apabila ditarik benang merah dalam sebuah kesimpulan pada umumnya, maka masuk kepada klasifikasi baik. Dapat di ujikan dengan konversi yang dilakukan seperti pada tabel 7 :

Tabel 7

Klasifikasian Value Hasil Belajar

\begin{tabular}{|c|c|c|c|}
\hline Intensitas & Rentan & $\%$ & Ket \\
\hline 0 & $0-21$ & $-\%$ & Buruk \\
\hline 0 & $22-41$ & $-\%$ & Kurang \\
\hline 0 & $42-61$ & $-\%$ & Sedang \\
\hline 30 & $62-81$ & $93,75 \%$ & Bagus \\
\hline 2 & $82-100$ & $6,25 \%$ & Ideal \\
\cline { 1 - 2 } 32 & Total & $100 \%$ & \\
\hline
\end{tabular}

Berlandaskan tabel 7 dapat dilakukan langkah pengkonversian kedalam bentuk lingkaran diagram 2 seperti berikut :

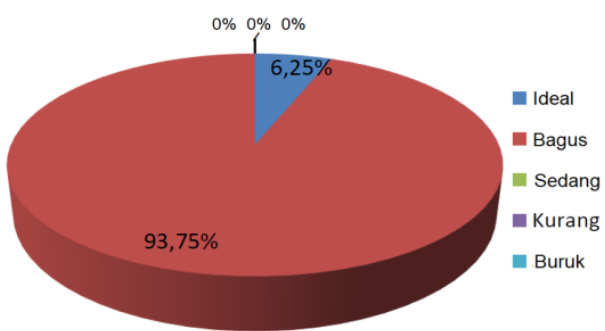

Lingkaran Diagram 2. Konversi Value Nilai Belajar 
Berlandaskan tabel 7 yang dikonversi ke diagram batang 1, dilihat level persentase bagus berada pada angka $93 \%$ lebih. Serta level persentase ideal berada di angka 6\% lebih. Seperti yang dilakukan untuk mengukur kadar aktif mahasiswa, dapat pula ditarik benang merah kesimpulan terkait level nilai mahasiswa di kategori Baik. Artinya mahasiswa dalam setiap mata kuliah memiliki rerata nilai yang baik. Benang merah yang telah ditarik dapat pula dikonversi ke diagram batang 2 berikut :

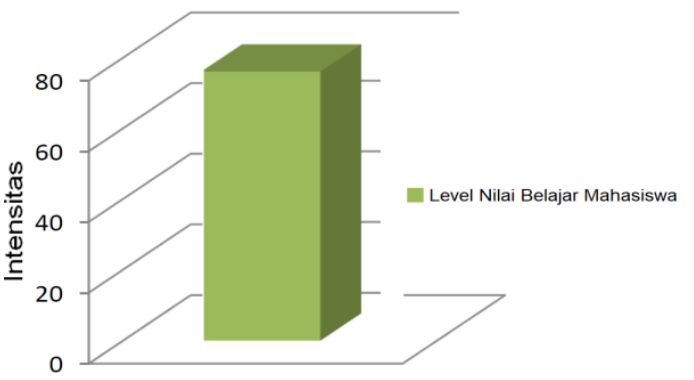

Diagram Batang 2. Persentase Level Nilai Belajar Mahasiswa

Berikutnya tes normalitas guna mengetahui komponen yang ada, di normal atau tidak normal. Acuan yang dipergunakan mengetahui kondisi normal atau tidak normal yakni $p$ lebih besar dari angka 0,05 kategori normal. Apabila $p$ tidak lebih besar dari angka 0,05 kategori tidak normal. Dibuktikan pada tabel 8 :

\section{Tabel 8}

Result Tes Normalitas

\begin{tabular}{|c|c|c|}
\hline Eksplanasi & Nilai & Aktif \\
\hline Rerata & 76,9 & 3,12 \\
\hline Persebaran Angka & 4,53 & 0,62 \\
\hline Rerata Persebaran & 0,22 & 0,13 \\
\hline+ & 0,22 & 0,13 \\
\hline- & 0,22 & 0,08 \\
\hline Tes Normalitas & 1,25 & 0,75 \\
\hline Tes 2 Arah & 0,089 & 0,62 \\
\hline
\end{tabular}

Seperti yang ditampilkan pada tabel 8 , terlihat jika angka seluruh komponen wujudnya lebih besar angkanya dari angka 0,05 , oleh karenanya dapat diklasifikasikan normal. Sesuai dengan ketetapan yang berlaku, apabila klasifikasi dikatakan normal, maka kelangsungan proses penelitian, dapat dilaksanakan.

Lanjutan proses penelitian berikutnya yakni tes asumsi kesamaan atau tes homogenitas. Tujuannya untuk melihat keseragaman atau ketidakseragaman tipe sampel dalam bentuk irisan komponen populasi. Adapun acuannya apabila $F_{\text {hitung }}$ lebih kecil dari $\mathrm{F}_{\text {tabel }}$ kemudian $p$ mempunyai angka nilai yang lebih besar nilainya dari angka 0,05, dikatakan seragam (homogen). Kebalikannya apabila $F_{\text {hitung }}$ lebih besar dari $\mathrm{F}_{\text {tabel }}$ kemudian $p$ memiliki angka nilai yang lebih kecil nilainya dari angka 0,05 , dikatakan tidak seragam (non homogen). Ditampilkan di tabel 9:

Tabel 9

Result Tes Keseragaman

\begin{tabular}{|c|c|c|}
\hline Komposisi & $\begin{array}{c}\text { H Uji } \\
\text { Homogen }\end{array}$ & $\begin{array}{c}\text { Tes } \\
\text { Sig N }\end{array}$ \\
\hline Nilai Mhs & 0,025 & 0,874 \\
\hline Level Aktif & 2,709 & 0,105 \\
\hline
\end{tabular}

Dilihat dari tabel 9, didapati jika nilai tes keseragaman nilainya lebih besar dari nilai acuan di angka 0,05. Artinya Ho terterima.

\section{KESIMPULAN}

Setelah melewati beberapa tahapan tes serta penghitungan, didapati bahwa level aktif serta akumulasi nilai dengan menggunakan media e-learning berbasis moodle dengan dinamika belajar dari rumah masih dapat menjaga serta mempertahankan mutu sesuai dengan acuan yang ditetapkan. Seluruh proses aktivitas pembelajaran dapat berjalan dengan baik sesuai dengan yang diharapkan serta ditargetkan.

\section{DAFTAR PUSTAKA}

Fatmawati, S. (2019). Efektivitas forum diskusi pada e-learning berbasis Moodle untuk meningkatkan partisipasi belajar. Refleksi Edukatika: Jurnal Ilmiah Kependidikan, 9(2).

Irawan, R., \& Surjono, H. D. (2018). 
Pengembangan e-learning berbasis moodle dalam peningkatkan pemahaman lagu pada pembelajaran bahasa inggris. Jurnal Inovasi Teknologi Pendidikan, 5(1), 1-11.

Jamaludin, J., Purba, R. A., Effendy, F., Muttaqin, M., Raynonto, M. Y., Chamidah, D., Rahman, M. A., Simarmata, J., Abdillah, L. A., \& Masrul, M. (2020). Tren Teknologi Masa Depan. Yayasan Kita Menulis.

Juita, R. (2019). Meningkatkan Hasil Belajar IPA Melalui Metode Eksperimen Pada Siswa Kelas IV SDN 02 Kota Mukomuko. IJIS Edu: Indonesian Journal of Integrated Science Education, 1(1), 43-50.

Khasanah, D. R. A. U., Pramudibyanto, H., \& Widuroyekti, B. (2020). Pendidikan dalam masa pandemi covid-19. Jurnal Sinestesia, 10(1), 41-48.

Mudawamah, N. S. (2020). Perilaku Pengguna Internet: Studi Kasus Pada Mahasiswa Jurusan Perpustakaan Dan Ilmu Informasi Uin Maulana Malik Ibrahim. BIBLIOTIKA: Jurnal Kajian Perpustakaan Dan Informasi, 4(1), 107-113.

Muhammad, H., Murtinugraha, R. E., \& Musalamah, S. (2020). Pengembangan media pembelajaran e-learning berbasis moodle pada mata kuliah metodologi penelitian. Jurnal Pensil: Pendidikan Teknik Sipil, 9(1), 54-60.

Purba, R. A. (n.d.). Kampus Merdeka Dalam
New Normal: Risiko Dan Kesempatan. Kampus Merdeka Seri 3: Mengenal Risiko Sistem Kampus Merdeka Di Masa New Normal, 95.

Purba, R. A., \& Verawardina, U. (2021). Deteksi Mahasiswa Yang Dapat Menyusun Tugas Akhir dengan Metode Visekriterijumsko Kompromisno Rangiranje (VIKOR). Techno. Com, 20(2), 210-220.

Rijal, A., \& Sofiarini, A. (2019). Pengembangan E-Learning Mata Kuliah Pembelajaran Matematika SD Berbasis Aplikasi Moodle Di Pgsd. Jurnal Basicedu, 3(4), 2071-2082.

Rizal, S., \& Walidain, B. (2019). Pembuatan Media Pembelajaran E-Learning Berbasis Moodle Pada Matakuliah Pengantar Aplikasi Komputer Universitas Serambi Mekkah. Jurnal Ilmiah Didaktika: Media Ilmiah Pendidikan Dan Pengajaran, 19(2), 178-192.

Sudarmanto, E., Purba, R. A., Nur, N. K., Revida, E., Hasibuan, A., Recard, M., Samsir, S., Simbolon, I., Chaerul, M., \& Tambunan, E. H. (2021). Pengembangan Budaya Akademik. Yayasan Kita Menulis.

Verawardina, U., \& Jama, J. (2018) Philosophy TVET Di Era Derupsi Revolusi Industri 4.0 Di Indonesia. Jurnal Filsafat Indonesia, 1(3), 104111. 